of fall in the sampled kilns were high. The musculoskeletal disorder related pain and discomfort was experienced by 73 per cent of working children in Bhaktapur and 58 per cent in Sarlahi. It was identified that work related injuries in young workers majorly affected upper and lower limbs. The odds ratio suggests that young workers were 8 times more likely to experience trouble or body pain compared to non-working children.

Discussion This study finds that presence of inferior physical environment, working conditions and practices has contributed to musculoskeletal injuries and problems exposing young workers to risks and hazards. This study was based on a small sample; nevertheless it portrays an overview of musculoskeletal disorders in the brick kilns focusing on young workers.

\section{REAL-TIME BIOFEEDBACK AND ITS ABILITY TO AFFECT CHANGES IN SPINAL POSTURE DURING REPETITIVE LIFTING}

${ }^{1}$ MG Boocock, 'Yanto Naude, ${ }^{2}$ Jeff Kilby, ${ }^{1} \mathrm{GA}$ Mawston. ${ }^{1}$ Health and Rehabilitation Research Institute, Auckland University of Technology, Auckland, New Zealand; ${ }^{2}$ School of Engineering, Computing and Mathematical Sciences, Auckland University of Technology, Auckland, New Zealand

\subsection{6/oemed-2018-ICOHabstracts.766}

Introduction Low back pain (LBP) is the leading cause of disability globally. Occupational risk factors associated with LBP include heavy, repetitive lifting, and awkward and flexed postures. Studies suggest younger people may be at an increased risk of LBP compared to older individuals. Postural feedback as an early intervention may provide a viable preventative approach for reducing the risk of LBP in the workplace.

Methods Thirty-four healthy, young participants were randomly allocated biofeedback (BF) or no biofeedback (NBF). Participants lifted a box weighing $13 \mathrm{~kg}$ at a frequency of 10 lifts per minute for up to $20 \mathrm{~min}$. Real-time biofeedback on lumbar posture was provided using two wireless inertial sensors attached to the lumbar spine and sacrum. The BF group received an audible cue when lumbar flexion exceeded $80 \%$ maximum flexion. Three-dimensional motion analysis and ground reaction forces were used to estimate moments at the base of the spine and on the passive structures of the lumbar spine. Participants rated perceived exertion throughout the task using Borg's scale.

Results Both the BF and NBF groups increased lumbar flexion over the duration of the lifting task, although the rate of change (slope) of peak lumbar flexion with BF was significantly less compared to $\mathrm{NBF}(\mathrm{p}=0.009)$. Normalised bending moments resisted by passive structures of the spine were higher in the $\mathrm{NBF}$ group $(0.7 \mathrm{Nm} / \mathrm{kg})$ compared to the $\mathrm{BF}$ group $(0.12 \mathrm{Nm} / \mathrm{kg})$ at $20 \mathrm{~min}$. The $\mathrm{BF}$ group demonstrated lower levels of perceived exertion.

Discussion Real-time biofeedback provides a viable approach to increase spinal postural awareness during repetitive lifting tasks, helping to reduce loads on the passive structures of the lumbar spine. A simple wireless inertial system for monitoring posture has potential for use in the work environment, and further evaluations should be undertaken to determine the long-term effectiveness of this approach.

\section{INVESTIGATION ON THE PREVALENCE OF MUSCULO- SKELETAL DISORDERS AMONG JUTE MILL WORKERS IN INDIA}

${ }^{1}$ Somnath Gangopadhyay*, ${ }^{2}$ Sayantika Das, ${ }^{2}$ Shreya Sinha, ${ }^{3}$ Santi Ranjan Dasgupta, ${ }^{4}$ Subrata Goswami. 'Professor; Occupational Ergonomics Laboratory, Department of Physiology, University College of Science and Technology, University of Calcutta, Kolkata, India; ${ }^{2}$ Research Scholar; Occupational Ergonomics Laboratory, Department of Physiology, University College of Science and Technology, University of Calcutta, India; ${ }^{3}$ Research Investigator; ESI Institute of Pain Management, ESI Hospital, Sealdah, Kolkata, West Bengal, India; ${ }^{4}$ Coarse coordinator; ESI Institute of Pain Management, ESI Hospital, Sealdah, Kolkata, West Bengal, India

\subsection{6/oemed-2018-ICOHabstracts.767}

Introduction Musculoskeletal disorders (MSDs) are reported maximum among jute mill workers of India. The present study is designed to find out the actual magnitude of the problems among jute mill workers and to identify the possible associations between discomforts and working postures of these workers.

Methodology This study was conducted among eight selected jute mills of India. 717 male jute mill workers actively engaged in work at least for one year were randomly selected in this study. Subjects with self-reported MSD complaints for at least last 12 weeks were included. A detailed posture analysis was performed among them by Ovako Working Posture Assessment System (OWAS) method.

Results Among all participants 55\% had complained Chronic Low Back Pain (CLBP). Age had an important association with CLBP. Subjects in the age group of 40-59 years were more likely to have pain $(p=0.02)$. Regarding ergonomic risk factors, lifting of load of more than $20 \mathrm{~kg}(p=0.04)$ and repetitive movements of limbs $(p=0.03)$ had significant associations with CLBP.

Discussion Present study identifies a significant prevalence of CLBP among jute mill workers. Regarding ergonomic risk factors, the study has identified that MSD is significantly associated with work related awkward postures, lifting of load above $20 \mathrm{~kg}$, repetitive movements of limbs and prolonged standing during work. Jute mill workers are exposed to heavy workload with repetitive and forceful motions, which generally adopt awkward and uncomfortable postures and carrying of excessive loads that ultimately has got a great impact on their health. Therefore, this study suggests the urgent need for work place interventions for improvement of work related health of 3,50,000 Jute workers of India.

\section{RATING FORCE REQUIRED TO PERFORM SELECTED WORK ACTIVITIES}

ZW Jóźwiak* ${ }^{*}$ M Dania, M Kosobudzki, A Bortkiewicz. Department of Work Physiology and Ergonomics, Nofer Institute of Occupational Medicine, Łódź, Poland

\subsection{6/oemed-2018-ICOHabstracts.768}

Introduction The rules for the use of force when performing work activities are specified for women and men in the Ordinance of the Minister of Labour and Social Policy of 14 March 2000 on health and safety at work in manual transport and later changes Ordinance of the Minister of Family, Labour and Social Policy of 25 April 2017. In particular, these rules apply to manual transport, 